\title{
Delivering Physical Activity Strategies That Work: Active People, Healthy Nation ${ }^{\mathrm{SM}}$
}

\author{
Thomas L. Schmid, Janet E. Fulton, Jean M. McMahon, Heather M. Devlin, Kenneth M. Rose, \\ and Ruth Petersen
}

Active People, Healthy Nation ${ }^{\text {SM }}$ is an initiative led by the US Centers for Disease Control and Prevention to improve the health of 27 million Americans by 2027 by increasing their level of physical activity. ${ }^{1}$ An earlier commentary provided the rationale and an overall description of Active People, Healthy Nation ${ }^{\mathrm{SM}} .^{2} \mathrm{~A}$ core goal of this initiative is to galvanize action across communities, government and nongovernmental organizations, and institutions to use a set of proven strategies to increase physical activity (Figure 1). Every Active People, Healthy Nation ${ }^{\mathrm{SM}}$ strategy can be designed to support equitable and inclusive access to opportunities for physical activity for all people, regardless of age, race, education, socioeconomic position, disability status, sexual orientation, or geographic location. And, as illustrated in Figure 1, equity and inclusive access are at the foundation of all of these approaches. When these strategies engage people at the local level, they can ensure that activities are community driven.

The Centers for Disease Control and Prevention's Division of Nutrition, Physical Activity, and Obesity provides financial and technical support to help state and local health departments, land grant universities, and community organizations to improve physical activity levels in communities affected by health inequities.

This commentary describes strategies that have been proven to increase physical activity and factors to consider when selecting strategies to match community needs. The strategies are based on evidenced-based recommendations in The Guide to Community Preventive Services (The Community Guide) and supported by a scientific report from the Physical Activity Guidelines Advisory Committee. ${ }^{3,4}$

\section{What Works: Strategies to Increase Physical Activity}

The Community Guide has 4 types of findings: recommend against, insufficient evidence, recommend with sufficient evidence, and recommend with strong evidence. Seven strategies recommended as having sufficient or strong evidence of effectiveness by the Community Guide are described next.

\section{Activity-Friendly Routes to Everyday Destinations}

This strategy uses built environment approaches to create or enhance community characteristics to make physical activity easier, more appealing, and more accessible. When implemented successfully, the result is routes such as sidewalks, walking and hiking

The authors are with the Division of Nutrition, Physical Activity, and Obesity, Centers for Disease Control and Prevention, Atlanta, GA, USA. Fulton (jkf2@cdc. gov) is corresponding author. trails, bicycle lanes, and public transit that connect to destinations such as parks, green spaces, stores, homes, schools, worksites, and libraries. ${ }^{5,6}$ Communities with activity-friendly features report higher levels of physical activity among their residents than those without these features. ${ }^{7,8}$

Several policy approaches can be used to implement this strategy. Complete Streets policies support safe and convenient access to streets for all users through features such as physically protected bike lanes, dedicated space for transit, accessible transit stops, frequent crossing opportunities, accessible pedestrian signals, and curb extensions. ${ }^{9}$ Communities can develop comprehensive or master plans to guide long-term development, ${ }^{10}$ and zoning policies can influence land use (eg, commercial vs. residential). Comprehensive or master plans often guide zoning codes and other regulations, which can promote physical activity by allowing a mix of residential and commercial development or requiring sidewalks. ${ }^{11}$

Promoting active travel to and from school can increase physical activity in elementary and middle school students. One approach is Safe Routes to School, which promotes environmental changes through infrastructure projects and noninfrastructure programing that make it easier for students to commute to school by walking, biking, or using other forms of active transportation. The Community Guide found that interventions designed to increase active travel to school can increase walking among students and reduce the risk of traffic-related injury. It also found that the economic benefits of these interventions can exceed their cost. Similar active travel initiatives have focused on improving the safety of routes to parks and senior centers. ${ }^{12}$

\section{Access to Places for Physical Activity}

Making current places easier to access or providing new places for people to be active is a proven strategy to increase physical activity. Parks and recreation centers can increase access by providing safe and attractive facilities; free or reduced-cost programs; and convenient pedestrian, cyclist, and auto entry points. Workplaces can have policies that encourage time off to participate in an activity class, help employees create social support groups, and provide environmental supports, such as showers and gyms. ${ }^{13,14}$

Another approach is the use of shared-use agreements between 2 or more organizations that allow broader access to the organizations' facilities. For example, churches or school districts may establish shared-use agreements that allow after-hours access to recreational facilities for community members. ${ }^{15,16}$

\section{School and Youth Programs}

Well-designed physical education in schools has been shown to increase the level of moderate- and vigorous-intensity physical activity among young people. Proven strategies include physical 


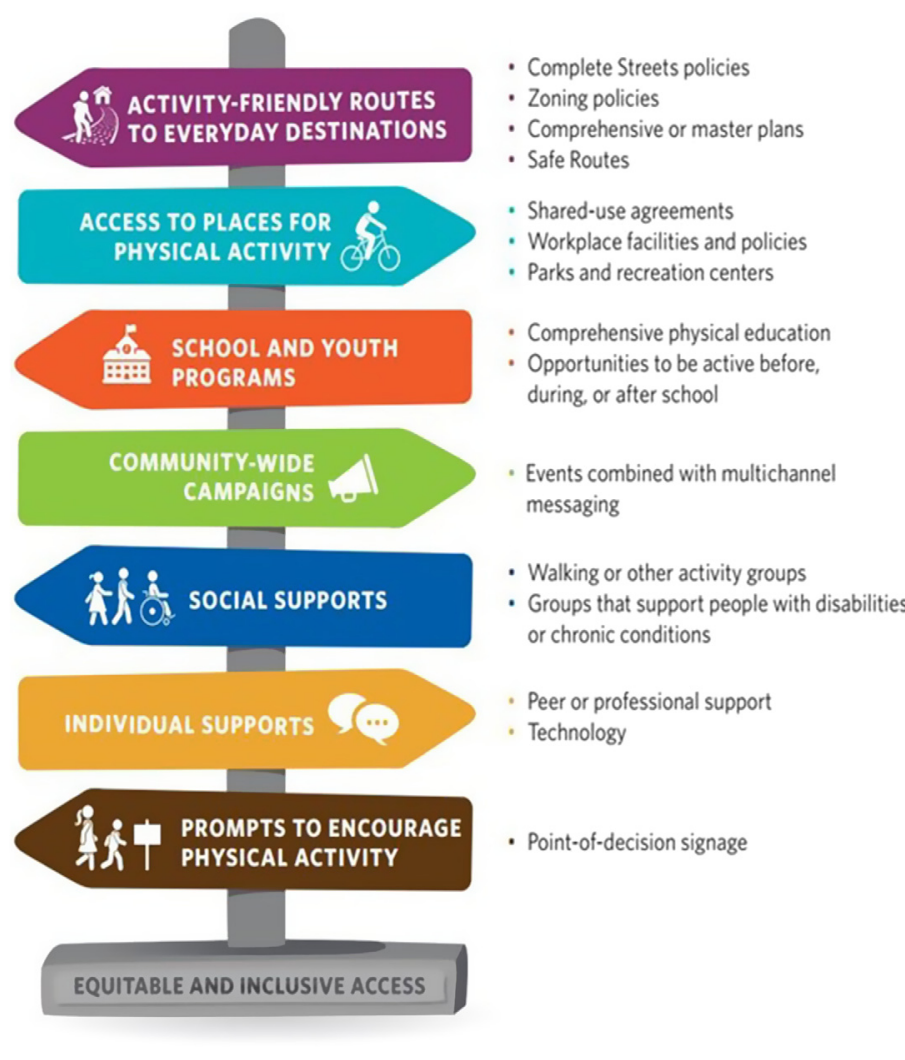

Figure 1 - Strategies recommended by The Community Guide as effective at promoting physical activity. Implementation approaches associated with these strategies are listed on the right.

education curricula that increase physical activity knowledge and skills among students, modify traditional games so that more students are active for longer periods of time, substitute less active games with more active ones, and train teachers how to develop and implement lesson plans that include activity. Successful strategies for increasing student physical activity during recess and in other classes have also been identified. ${ }^{13,17,18}$ In addition, before- and after-school activities, such as team and individual sports, activity clubs, and intramural and interscholastic sports, can contribute to an active student body. ${ }^{19}$

\section{Community-Wide Campaigns}

Community-wide campaigns are sustained, high-intensity efforts designed to reach large numbers of people from a wide range of groups based on social, economic, and other factors, including age, sex, race, and ethnicity. They seek to promote physical activity by combining several strategies, such as media coverage and promotions, risk factor screening and education, community events, and policy and environmental changes. Community-wide campaigns typically include general and targeted media outreach, contests, counseling, support groups, and programmatic offerings such as classes. ${ }^{13}$ A campaign called Shape up Sommerville, which is described in a later section, is an example of a successful community-wide campaign. ${ }^{20}$

\section{Social Support}

These strategies build support for social networks and friendships to help people start, maintain, or increase physical activity. ${ }^{13}$ They include group activities such as buddy systems and walking and activity clubs (eg, hiking, cycling, trekking). For example, GirlTrek is an organization that promotes pride, independence, and social support for African American women by sponsoring regular walking sessions. ${ }^{21}$ Walk with a Doc was formed by a doctor to encourage his patients to walk more by hosting walking sessions and serving as an active role model. It has since grown to over 500 chapters worldwide, including groups led by medical students. ${ }^{22}$

\section{Individual Supports}

Individual supports or individually adapted health behavior change strategies focus on the specific needs of individuals and are delivered to individuals or groups. ${ }^{23}$ They build on a long history of effective behavior change interventions ${ }^{24}$ and are important complements to population-level strategies. They provide frequent feedback and various levels of reinforcement to help participants build skills, set goals, and solve problems. Programs can be promoted and delivered in multiple settings, including worksites, schools, churches, and social service organizations. Support and counseling can be provided by peer, lay, and professional counselors. Advances in technology allow feedback and motivational support through mechanisms such as telephone, text, and wearable activity monitors. ${ }^{23}$

\section{Prompts to Encourage Physical Activity}

Signage or other prompts located at points where people make decisions about being active are an effective strategy to increase physical activity. Posters, signs, or media placed at elevators or escalators are associated with more people choosing an active option, such as taking the stairs. ${ }^{25,26}$ Prompts are an effective and enduring way for worksites and commercial locations, such as malls or airports, to help people make an active choice. ${ }^{27}$ These low-cost strategies can also be part of a larger campaign that includes additional programmatic, policy, and environmental interventions. Another strategy for encouraging active choices is wayfinding, which is the process by which a person determines his/her position in a physical space and navigates a route. Wayfinding strategies were successfully used in London before the Olympics as a way to reduce the burden on the subway system. Signs were installed throughout the city to encourage walking. ${ }^{6}$

\section{Where to Begin: Choosing a Strategy to Implement}

Public health is what we do together as a society to ensure conditions in which everyone can be healthy. ${ }^{28}$ Public health strategies should focus on actions that are sustainable and have the widest reach, which are generally those that emphasize policy, systems, and environmental changes. ${ }^{29}$ For example, accessible routes to everyday destinations can be long lasting and reach many people, although they can also take significant time and resources to implement. ${ }^{30}$ Communities and organizations can choose a smaller-scale strategy to start, but we encourage them to consider strategies with the greatest potential reach and impact within their resources, including ones that will reduce physical activity disparities. For example, a community with an existing Complete Streets policy could begin by including sidewalks and cycling routes in its budget and routine maintenance plans, which will help increase the quality and quantity of these activity-friendly features. 
A community without such a policy might begin with a simple wayfinding approach that includes motivational messages and signs that direct people to opportunities for physical activity. Others may choose to begin or expand a social support program such as GirlTrek or mall walking. ${ }^{21,31}$ Communities can also consider layering complementary strategies at multiple levels to increase reach, reduce disparities, and enhance sustainability. For example, a city using GirlTrek could help participants be trained through a program like The Walking College, which is a national fellowship that teaches people how to become leaders in creating stronger, more equitable, sustainable, and livable communities. ${ }^{32}$ Through this training, GirlTrek members could learn how to advocate for improvements in walkability in neighborhoods with the greatest need, which could lead to adoption of a citywide Complete Streets policy.

One way to choose a strategy is to compare its level of impact and investment. "Impact" refers to population-level improvements in behavior (physical activity) and health. "Investments" refer to the governmental, fiscal, physical, and personnel resources required as well as the time that will be needed for these investments to have an impact. Figure 2 provides examples of different levels of investment in the activity-friendly routes to everyday destinations strategy. The placement of the examples on the figure illustrates how different levels of investment can result in different levels of impact over varying timeframes. In general, we assume that additional resources can increase the impact and shorten the time required for these or other Active People, Healthy Nation ${ }^{\text {SM }}$ strategies to have an effect (Figure 2). For example, the small city of Montevallo (Alabama) created temporary crosswalks and improved walking routes using hay bales and traffic cones. To increase the long-term impact and durability of these efforts, the city could evaluate its efforts and use the results to guide future strategies to increase walkability. In Tucson, AZ, a group called the Living Street Alliance worked with community members and government officials to pass a Complete Streets ordinance. As new streets are built or existing ones repaired, Complete Streets principles will guide their design, creating a more walkable and pedestrian-friendly city. Officials in Mueller, Texas, used a master plan to create a mixed-use community where people can live, work, and play. The community incorporates activity-friendly design elements, including safe sidewalks and other routes to everyday destinations. Although such efforts can require years or decades to complete, their effects can be widespread and enduring. ${ }^{5,8,12,14}$ It is important to recognize that the scale of these approaches will have an important influence on their ultimate impacts. A municipalwide Complete Streets policy, once fully implemented, could have a larger total population impact than a Master Planned community, which can influence the behavior of its residents but have little impact on the larger metropolitan area.

Communities can also expand, adapt, or combine other Active People, Healthy Nation ${ }^{\mathrm{SM}}$ strategies to accelerate implementation and increase impact. For instance, the Shape Up Somerville program began as a research study on obesity prevention and control among elementary school students in Somerville, Massachusetts. Because of its early success, the city gradually expanded the program into a community-wide campaign offering nutrition, fitness, and positive lifestyle opportunities to children and adults. The cost effectiveness of this program is attributed to its comprehensive, community-wide implementation. ${ }^{20}$

Adding or "layering" strategies ${ }^{13,30}$ can increase reach and impact and help more people become active while reducing inequities that may result when interventions benefit some community members more than others. ${ }^{33,34}$ For instance, a community that adopts a Complete Streets policy could also use a communitywide campaign to promote physical activity, provide access to programs such as Safe Routes to School, ${ }^{35}$ and add wayfinding strategies to reach more residents. These strategies are well suited for being tailored to specific community needs. For instance, the REACH (Racial and Equity Approaches to Community Health) program has successfully integrated community participatory research into efforts to reduce disparities and increase physical activity. ${ }^{36}$

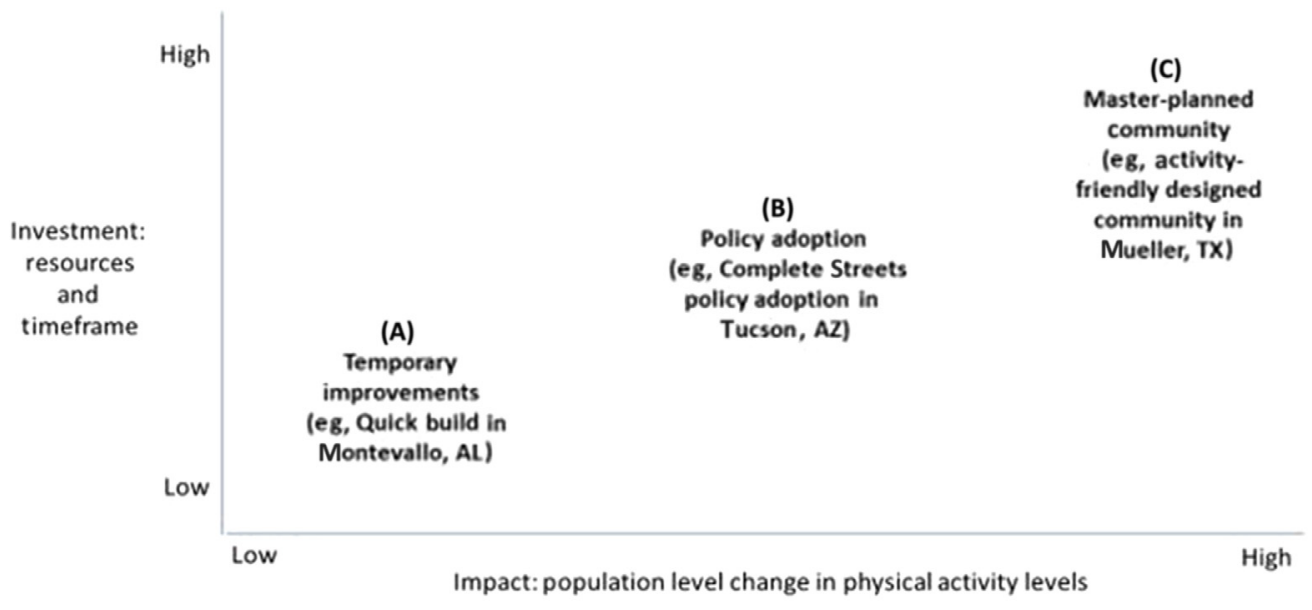

Figure 2 - Potential level of impact of 3 strategies designed to create activity-friendly routes to everyday destinations with different levels of program intensity and investment in time and resources. Impact refers to population-level improvements in behavior (physical activity) and health. Investments refer to the political, fiscal, physical, and personnel investments required as well as the time required for these investments to have an impact. (A) Low: Montevallo, AL created temporary crosswalks and walking routes near a busy school crossing using hay bales and traffic cones. (B) Middle: Tucson, AZ adopted a Complete Streets policy that will promote streets designed to be safe and convenient for pedestrians and cyclists. As existing streets are refurbished or new streets developed, these principles will guide designs. (C) High: Mueller, TX is a new community that includes design elements in its master plan and zoning ordinances, such as mixed uses, accessible green space, and attractive everyday destinations, that encourage recreational and transportation-related physical activity, such as walking, jogging, and cycling. 


\section{Conclusion}

As illustrated on the signpost in Figure 1, health equity is the foundation of the Active People, Healthy Nation ${ }^{\text {SM }}$ initiative. Although inequities in physical activity levels persist across population groups, the strategies in Figure 1 can be adapted to address these inequities through changes in programs, policies, systems, and the environment. Some strategies can be used to improve physical activity levels among individuals, whereas others focus on community-wide changes. Communities can also add and combine strategies depending on their resources, needs, and context. Using these proven strategies, Active People, Healthy Nation ${ }^{\mathrm{SM}}$ is galvanizing action across communities, governmental and nongovernmental organizations, and institutions to increase physical activity levels across the United States. The launch of this initiative marks the beginning of a journey to improve the health of 27 million Americans by 2027 through increases in physical activity.

\section{References}

1. Centers for Disease Control and Prevention. About Active People Healthy Nation. 2020. https://www.cdc.gov/physicalactivity/active peoplehealthynation/about-active-people-healthy-nation.html. Accessed December 1, 2020.

2. Fulton JE, Buchner DM, Carlson SA, et al. CDC's Active People, Healthy Nation $^{\text {SM }}$ : creating an active America, together. $J$ Phys Act Health. 2018;15(7):469-473. PubMed ID: 29932005 doi:10.1123/ jpah.2018-0249

3. 2018 Physical Activity Guidelines Advisory Committee. 2018 Physical Activity Guidelines Advisory Committee Scientific Report. Washington, DC: US Department of Health and Human Services; 2018.

4. Guide to Community Preventive Services. What works fact sheet: increasing physical activity. https://www.thecommunityguide.org/ resources/what-works-increasing-physical-activity. Accessed December 17, 2019.

5. Guide to Community Preventive Services. Physical activity: built environment approaches combining transportation system interventions with land use and environmental design. Systematic Review. 2016. https://www.thecommunityguide.org/resources/what-worksincreasing-physical-activity. Accessed June 8, 2020.

6. AIG. Legible London: a wayfinding study. 2006. http://applied wayfinding.com/projects/legible-london-a-wayfinding-study/. Accessed June 10, 2020.

7. Calise TV, Heeren T, DeJong W, Dumith SC, Kohl HW 3rd. Do neighborhoods make people active, or do people make active neighborhoods? Evidence from a planned community in Austin, Texas. Prev Chronic Dis. 2013;10:E102. PubMed ID: 23786909 doi: $10.5888 /$ pcd10.120119

8. Lee C, Zhu X, Xu M, Lee H, Ory M. Moving to an activity-friendly community can increase physical activity. Paper presented at: Active Living Conference; February 5, 2020; Orlando, FL.

9. Smart Growth America. What are complete streets? https://smartgrowth america.org/program/national-complete-streets-coalition/publications/ what-are-complete-streets/. Accessed June 9, 2020.

10. American Planning Association. Planning and community health: Plan4Health. https://www.planning.org/nationalcenters/health/ psecoalitions/. Accessed June 9, 2020.

11. Chriqui JF, Nicholson LM, Thrun E, Leider J, Slater SJ. More active living-oriented county and municipal zoning is associated with increased adult leisure time physical activity-United States,
2011. Environ Behavior. 2016;48(1):111-130. PubMed ID: 27587898 doi:10.1177/0013916515611175

12. Guide to Community Preventive Services. Physical activity: interventions to increase active travel to school. 2018. https://www.thecommunity guide.org/findings/physical-activity-interventions-increase-active-travelschool. Accessed June 9, 2020.

13. Kahn EB, Ramsey LT, Brownson RC, et al. The effectiveness of interventions to increase physical activity. A systematic review. Am J Prev Med. 2002;22(suppl 4):73-107. doi:10.1016/S0749-3797(02) 00434-8

14. Guide to Community Preventive Services. What works: increasing physical activity, evidence-based interventions for your community. 2017. https://www.thecommunityguide.org/resources/what-worksincreasing-physical-activity. Accessed June 9, 2020.

15. Omura JD, Carlson SA, Paul P, Sliwa S, Onufrak SJ, Fulton JE. Shared use agreements between municipalities and public schools in the United States, 2014. Prev Med. 2017;95:S53-S59. PubMed ID: 27658899 doi:10.1016/j.ypmed.2016.09.026

16. Spengler JO, Carroll MS, Connaughton DP, Evenson KR. Policies to promote the community use of schools: a review of state recreational user statutes. Am J Prev Med. 2010;39(1):81-88. PubMed ID: 20547280 doi:10.1016/j.amepre.2010.02.019

17. Division of Population Health National Center for Chronic Disease Prevention and Health Promotion C. Healthy schools: physical education and physical activity. https://www.cdc.gov/healthyschools/ physicalactivity/index.htm. Accessed June 9, 2020.

18. Guide to Community Preventive Services. Physical activity: enhanced school-based physical education. https://www.thecommunityguide.org/ findings/physical-activity-enhanced-school-based-physical-education. Accessed August 20, 2020.

19. Lonsdale C, Rosenkranz RR, Peralta LR, Bennie A, Fahey P, Lubans DR. A systematic review and meta-analysis of interventions designed to increase moderate-to-vigorous physical activity in school physical education lessons. Prev Med. 2013;56(2):152-161. PubMed ID: 23246641 doi:10.1016/j.ypmed.2012.12.004

20. Coffield E, Nihiser A, Carlson S, et al. Shape up Somerville's return on investment: multi-group exposure generates net-benefits in a child obesity intervention. Prev Med Rep. 2019;16:100954. PubMed ID: 31463186 doi:10.1016/j.pmedr.2019.100954

21. Girl Trek. GirlTrek. https://www.girltrek.org/. Accessed June 9, 2020.

22. Walk with a Doc. Walk with a Doc. 2020. https://walkwithadoc.org/. Accessed June 9, 2020.

23. King AC, Whitt-Glover MC, Marquez DX, et al. Physical activity promotion: highlights from the 2018 physical activity guidelines advisory committee systematic review. Med Sci Sports Exerc. 2019; 51(6):1340-1353. PubMed ID: 31095090 doi:10.1249/MSS.0000 000000001945

24. Brown DR, Morgan J, Day K, Gates S, Heath GW, Brownson RC. Implementing physical activity interventions in communities: considerations for practitioners. In: Heath GW, ed. Physical Activity \& Public Health: A Practitioner's Guide. Washington, DC: APHA; 2019:51-95.

25. Soler RE, Leeks KD, Buchanan LR, Brownson RC, Heath GW, Hopkins DH. Point-of-decision prompts to increase stair use. A systematic review update. Am J Prev Med. 2010;38(suppl 2): S292-S300. PubMed ID: 20117614 doi:10.1016/j.amepre.2009. 10.028

26. Nocon M, Muller-Riemenschneider F, Nitzschke K, Willich SN. Review article: increasing physical activity with point-of-choice prompts—a systematic review. Scand J Public Health. 2010;38(6): 633-638. PubMed ID: 20601438 doi:10.1177/1403494810375865 
27. Fulton JE, Frederick GM, Paul P, Omura JD, Carlson SA, Dorn JM. Increasing walking in the Hartsfield-Jackson Atlanta International Airport: the walk to fly study. Am J Public Health. 2017;107(7): 1143-1149. PubMed ID: 28520493 doi:10.2105/AJPH.2017.303766

28. DeSalvo KB, Wang YC, Harris A, Auerbach J, Koo D, O'Carroll P. Public Health 3.0: A Call to Action for Public Health to Meet the Challenges of the 21st Century. Prev Chronic Dis. 2017;14:170017. doi:10.5888/pcd14.170017

29. Frieden TR. A framework for public health action: the health impact pyramid. Am J Public Health. 2010;100(4):590-595. PubMed ID: 20167880 doi:10.2105/AJPH.2009.185652

30. Brownson RC, Haire-Joshu D, Luke DA. Shaping the context of health: a review of environmental and policy approaches in the prevention of chronic diseases. Annu Rev Public Health. 2006;27(1):341-370. PubMed ID: 16533121 doi:10.1146/annurev.publhealth.27.021405.102137

31. Farren L, Belza B, Allen P, et al. Mall walking program environments, features, and participants: a scoping review. Prev Chronic Dis. 2015;12:E129. PubMed ID: 26270743 doi:10.5888/pcd12.150027
32. America Walks. Walking College. https://americawalks.org/walking college/. Accessed June 8, 2020.

33. Lorenc T, Petticrew M, Welch V, Tugwell P. What types of interventions generate inequalities? Evidence from systematic reviews. J Epidemiol Community Health. 2013;67(2):190-193. PubMed ID: 22875078 doi:10.1136/jech-2012-201257

34. Backholer K, Beauchamp A, Ball K, et al. A framework for evaluating the impact of obesity prevention strategies on socioeconomic inequalities in weight. Am J Public Health. 2014;104(10):e43-e50. PubMed ID: 25121810 doi:10.2105/AJPH.2014.302066

35. Safe Routes Partnership. Safe routes. https://www.saferoutes partnership.org/. Accessed June 9, 2020.

36. Kosoko-Lasaki O, Ekúndayò OT, Smith J, et al. Urban minority community safety and its impact on physical activity: the center for promoting health and health equity-racial and ethnic approaches to community health (CPHHE-REACH) initiative. J Natl Med Assoc. 2019;111(3):334-344. PubMed ID: 30711288 doi:10.1016/j.jnma. 2019.01.001 